\title{
Giant placental chorioangioma discovered at 29 weeks' gestation: a case report
}

\author{
Fatimazahra Cherrabi ${ }^{1}$, Mounir Moukit ${ }^{1 *}$, Jaouad Kouach ${ }^{1,2}$, \\ Driss Moussaoui Rahali, ${ }^{1,2}$, Mohammed Dehayni ${ }^{2,3}$
}

\author{
${ }^{1}$ Department of Obstetrics and Gynecology, Military Training Hospital Mohammed V, Rabat, Morocco \\ ${ }^{2}$ Department of Medicine and Pharmacy, University Mohammed V, Rabat, Morocco \\ ${ }^{3}$ Department of Visceral Surgery and Obstetrics and Gynecology, Military Training Hospital Mohammed V, Rabat, \\ Morocco
}

Received: 12 October 2017

Accepted: 08 November 2017

\author{
*Correspondence: \\ Dr. Mounir Moukit, \\ E-mail: moukitmounir@yahoo.com
}

Copyright: () the author(s), publisher and licensee Medip Academy. This is an open-access article distributed under the terms of the Creative Commons Attribution Non-Commercial License, which permits unrestricted non-commercial use, distribution, and reproduction in any medium, provided the original work is properly cited.

\begin{abstract}
Chorioangiomas are the commonest non-trophoblastic tumors of placenta with an estimated incidence of $1 \%$. The majority of them are small, asymptomatic and only found by careful pathologic examination of the placenta. Occasionally, they can attain a large diameter $(\geq 4-5 \mathrm{~cm})$ resulting in what is termed 'giant chorioangioma' with a high feto-maternal morbidity and mortality rates. We report a case of giant chorioangioma discovered accidentally during a routine obstetric ultrasound. Expectant management was adopted. Ultrasound follow-up revealed several fetal complications; an elective caesarean section was made giving birth to a premature new-born with enormous hepatosplenomegaly, died on the first day of life. Diagnosis and management of chorioangioma represents a stringent challenge for obstetricians due to its potentially serious antenatal complications.
\end{abstract}

Keywords: Feto-maternal outcome, Giant chorioangioma, Placenta, Ultrasound

\section{INTRODUCTION}

Chorioangiomas are the commonest non-trophoblastic benign neoplasms of placenta, characterized by the abnormal proliferation of vessels arising from chorionic tissue. The vast majority of them are small, asymptomatic and only found by careful pathologic examination of the placenta. ${ }^{1}$

Rarely, they can attain a large diameter ( $\geq 4-\mathrm{cm})$ resulting in what is called giant chorioangioma (GC) associated with a significant antenatal complications and neonatal mortality. ${ }^{2}$

We present a prenatally detected case of a GC that had adverse fetal and neonatal consequences.

\section{CASE REPORT}

A 29-year-old primigravida presented in our department at 29 weeks' gestation for a routine obstetric ultrasound. The pregnancy had been uneventful and two previous obstetrical ultrasounds, at 11 and 20 weeks' gestation, were normal. Obstetrical ultrasound scan showed a single viable intrauterine fetus corresponding to gestational age with no morphologic abnormality. Placenta was posterior with adequate amniotic liquor. In addition, a well-defined echogenic mass arising from the fetal surface of the placenta and measuring $16 \mathrm{~cm} \times 14 \mathrm{~cm}$ was seen, with numerous vessels in color Doppler, suggestive of GC (Figure 1). On physical examination, patient's vital signs were within normal range and she did not have any complaints. Clinical and ultrasound evaluations were arranged every two weeks to detect the appearance of 
possible feto-maternal complications. Ultrasound monitoring revealed, at 33 weeks' gestation, polyhydramnios (amniotic fluid index: $32 \mathrm{~cm}$ ), fetal anemia objectified by increased peak systolic velocity of the middle cerebral artery (Figure 2), fetal cardiomegaly and hepatomegaly with skin edema.

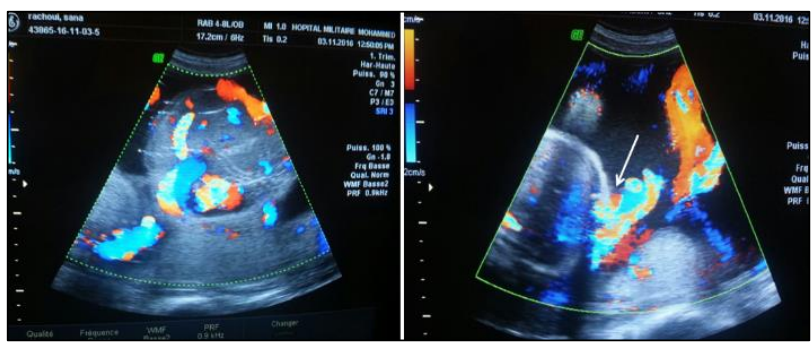

Figure 1: Giant echogenic mass in the vicinity of umbilical cord insertion (white arrow) with numerous vessels in color Doppler.

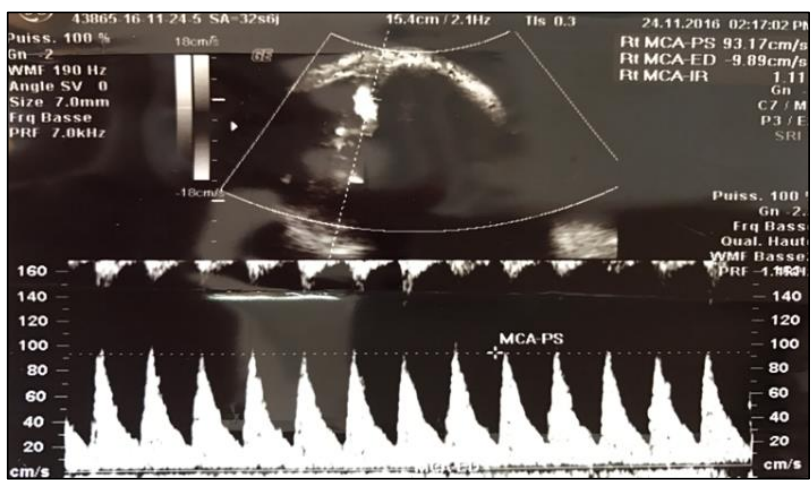

Figure 2: Increased peak systolic velocity of the middle cerebral artery.

Given severity of fetal complications, elective cesarean section was indicated after Betamethasone administration for acceleration of fetal lung maturity.

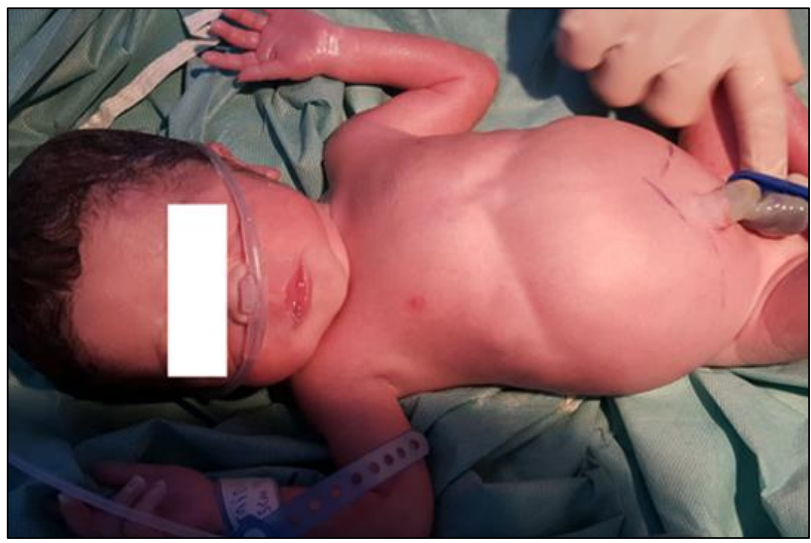

Figure 3: The new-born with enormous hepatosplenomegaly reaching the umbilicus.

The male newborn weighed 2050 grams with 8/10 Apgar scores at $1^{\text {st }}$ and $5^{\text {th }}$ minutes. Placenta was extracted completely and sent for histopathology. Clinical examination of the newborn revealed enormous hepatosplenomegaly (Figure 3) and lab investigations showed anemia (hemoglobin: $7.7 \mathrm{~g} / \mathrm{dl}$ ) with thrombocytopenia (platelet count: $70000 / \mathrm{mm}^{3}$ ).

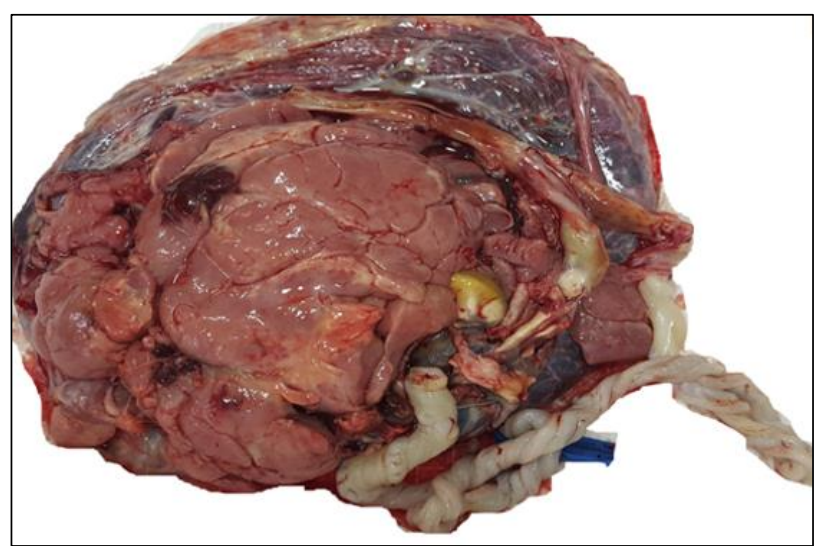

Figure 4: Macroscopic view of the mass in the fetal surface of placenta.

Unfortunately, the newborn died on the first day of life due to cardiorespiratory distress. Macroscopic examination of the placenta objectified a large lobulated mass, in the fetal surface, measuring $18 \mathrm{~cm} \times 15 \mathrm{~cm} \times 6 \mathrm{~cm}$ (Figure 4). The three-vessel umbilical cord was eccentrically placed. Microscopic examination revealed tumoral mass containing numerous proliferative thin walled capillaries separated by fibrous stroma with strong reactivity of endothelial cells using immunohistochemy for CD34 (Figure 5). The pathologic report was giant placental chorioangioma. The patient had an uneventful postoperative course and she was discharged home four days later.

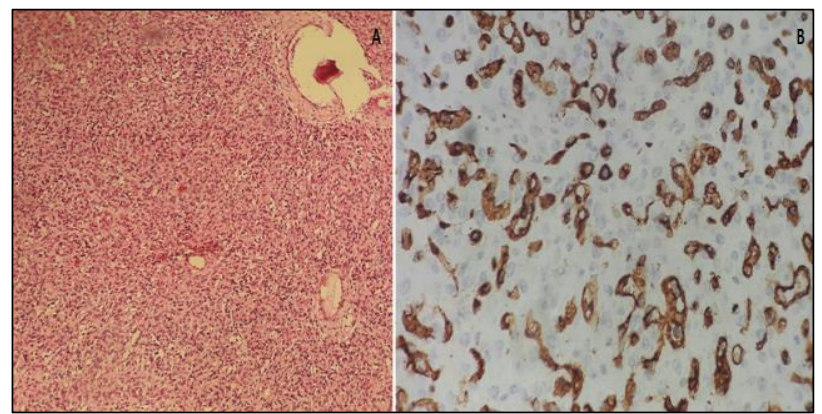

Figure 5: (A/HEx100) Numerous proliferative thin walled capillaries separated by fibrous stroma; (B)

Reactivity of endothelial cells using immunohistochemy for CD34.

\section{DISCUSSION}

Chorangioma is a non-trophoblastic benign vascular tumor of the placenta arising from the primitive chorionic mesenchyme. The estimated incidence is $1 \%$, but it is usually underestimated as the majority of them are small, 
asymptomatic and only found fortuitously during pathologic examination of the placenta. ${ }^{1,3}$ Moreover, GCs are indeed very rare with an incidence varying from $1 / 3500$ to $1 / 9000$ pregnancies. ${ }^{1,2}$ Risk factors of chorioangioma include primiparity, advanced maternal age, female fetus and twin pregnancies. ${ }^{1,4}$

In our case, primiparity was the only identified risk factor. In literature, the consensus about the association between the chorioangioma size and high fetal complications and neonatal mortality rates was replicated in the present case. ${ }^{5}$ Both the increased venous return to heart, due to the enlargement of feto-placental blood volume, and the reduced fetal cardiac after-load for tumor functional arteriovenous shunt can impair fetal heart reserve capacity, with possibility of congestive cardiac failure, oedema, hydrops, intrauterine growth restriction and finally fetal death. ${ }^{1,6}$ Polyhydramnios has been attributed to fluid transudation through walls of tumor vessels or to mechanical obstruction of umbilical vein by large tumor mass. ${ }^{5}$ To a certain extent, polyhydramnios increases the risks of preterm labor, placental abruption and postpartum hemorrhage. Fetal symptoms of hydrops can "mirror" and cause maternal complication called mirror syndrome, also known as Ballantyne syndrome, which disappears quickly after delivery. More rare complications such as pre-eclampsia, maternal ovarian luteinized cysts, fetal malformations and neonatal haemangiomatosis have been described. ${ }^{7,8,1}$ Ultrasound with Color Doppler Imaging (CDI) remains the investigation of choice for prenatal diagnosis of chorioangioma and follows up in case of expectative management, as was in the present case. It appears as a well circumscribed echogenic mass different from the rest of placenta. Along with the increase of gestation, it may have different echogenicity due to progressive necrosis, degeneration or calcification of the tumor. ${ }^{1}$

According to the blood flow, it not only can confirm the vascular channels in tumor, similar to fetal vessels, but also can predict the outcome of pregnancy. When CDI demonstrates poor or decreased intramural vascularity, the pregnancy often ends more favorably. ${ }^{9}$ There are some chorioangiomas without any blood flow in CDI, and their absence does not exclude the diagnosis. Recently, placental magnetic resonance imaging has been reported as an adjunct to ultrasound. This expensive modality is safe in pregnancy and has an ability to differentiate between chorioangioma and other placental pathologies by $\mathrm{T}$ weighting of the image. ${ }^{1,5}$ Histologically, three forms have been described: angiomatous, cellular and degenerate. Angiomatous being the most recurrent, with numerous proliferative blood vessels in various stages of differentiation from capillary to cavernous surrounded by placental stroma. ${ }^{3}$ These lesions are thus classified as placental hamartomas rather than true neoplasia. ${ }^{5}$ Immunohistochemically, the tumour cells show staining for CD31, CD34, factor VIII, GLUT1 and cytokeratin $18 .{ }^{3}$ Usually, chorioangiomas are treated with expectant management. For the complicated cases, the time of delivery depends on the severity and progression of the feto-maternal complications and the gestational age. When complications develop in third trimester, delivery should be indicated, as was in our patient. For GC, we recommended cesarean section unless they are in labor spontaneously. If severe fetal complications occur late in the second trimester, termination of pregnancy is not the preferred option for fetal prematurity, and some interventions can be used including supportive measures (serial amniodrainage or indomethacin therapy for polyhydramnios and intrauterine transfusions in case of fetal anemia) and definitive tumor devascularisation (ligation/clipping, fetoscopic laser coagulation, embolization, chemosclerosis with absolute alcohol injection or radiofrequency ablation of tumor vessels). ${ }^{10-13}$

\section{CONCLUSION}

Because of the potential complications resulting from giant chorioangioma, early prenatal diagnosis, close monitoring (every 1 week), proper treatment and delivery timely all play an important role in improving the fetomaternal outcome.

\section{ACKNOWLEDGMENTS}

Authors are thankful to the patient who permitted authors to present his history in this report.

\section{Funding: No funding sources Conflict of interest: None declared \\ Ethical approval: Not required}

\section{REFERENCES}

1. Zaigui W, Wensheng H. Clinical analysis of 26 patients with histologically proven placental chorioangiomas. Eu J Obstet Gynecol Reprod Biol. 2016;199:156-63.

2. Guschmann M, Henrich W, Entezami M, Dudenhausen JW. Chorioangioma: new insights into a well-known problem: results of a clinical and morphological study of 136 cases. J Perinat Med. 2003;31:163-9.

3. Kataria N, Singh A, Bedi PK. Giant placental chorangioma: a rare case report. J Clin Diagnostic Res. 2016;10:ED03-4.

4. Wou K, Chen MF, Mallozzi A, Brown RN, Shrim A. Pregnancy outcomes and ultrasonographic diagnosis in patients with histologically-proven placental chorioangioma. Placenta. 2011;32:671-4.

5. Marwah S, Bansal N, Gaikwad H, Sharma M. Giant chorioangioma of placenta: an infrequent placental cause for adverse feto-maternal outcome. Int $\mathbf{J}$ Reprod Contracept Obstet Gynecol. 2015;4:893-7.

6. Dhar H. Giant placental chorioangioma with intrauterine fetal death. JNMA. 2013;52:384-7.

7. Saltzman M, Drut M, Drut R. Luteinized cystic ovarian hyperplasia associated with placentomegaly 
due to chorangiomatosis. Fetal Pediatr Pathol 2005;24:31-7.

8. Hoeger PH, Maerker JM, Kienast AK, Syed SB, Harper JI. Neonatal haemangiomatosis associated with placental chorioangiomas: report of three cases and review of the literature. Clin Exp Dermatol. 2009;34:e78-80.

9. Jauniaux E, Ogle R. Color Doppler imaging in the diagnosis and management of chorioangiomas. Ultrasound Obstet Gynecol. 2000;15:463-7.

10. Quarello E, Bernard JP, Leroy B, Ville Y. Prenatal laser treatment of a placental chorioangioma. Ultrasound Obstet Gynecol. 2005;25:299-301.

11. Quintero RA, Reich H, Romero R, Johnson MP, Gonzalves L, Evans MI. In utero endoscopic devascularization of a large chorioangioma. Ultrasound Obstet Gynecol. 1996;8:48-52.

12. Kriplani A, Abbi M, Banerjee N, Roy KK, Takkar D. Indomethacin therapy in the treatment of polyhydramnios due to placental chorioangioma. J Obstet Gynaecol Res. 2001;27:245-8.

13. Lau TK, Leung TY, Yu SC, To KF, Leung TN. Prenatal treatment of chorioangioma by microcoil embolisation. BJOG. 2003;110:70-3.

Cite this article as: Cherrabi F, Moukit M, Kouach J, Rahali DM, Dehayni M. Giant placental chorioangioma discovered at 29 weeks' gestation: a case report. Int J Reprod Contracept Obstet Gynecol 2018;7:329-32. 